\title{
The clinical status and survival in elderly dialysis: example of the oldest region of France
}

\author{
Florence Glaudet ${ }^{1 *}$, Carine Hottelart ${ }^{2}$, Julien Allard ${ }^{1}$, Vincent Allot ${ }^{1}$, Frédérique Bocquentin ${ }^{1}$, Rémy Boudet ${ }^{3}$, \\ Béatrice Champtiaux ${ }^{2}$, Jean Pierre Charmes ${ }^{2}$, Monica Ciobotaru ${ }^{3}$, Zara Dickson ${ }^{2}$, Marie Essig ${ }^{1}$, Philippe Honoré ${ }^{3}$, \\ Céline Lacour ${ }^{1}$, Christian Lagarde ${ }^{2}$, Maria Manescu ${ }^{4}$, Pierre Peyronnet ${ }^{2}$, Jean Michel Poux ${ }^{4}$, Jean Philippe Rerolle ${ }^{1}$, \\ Michel Rincé ${ }^{1}$, Cécile Couchoud ${ }^{5}$, Jean Claude Aldigier ${ }^{1}$ and on behalf of REIN Limousin
}

\begin{abstract}
Background: The number of elderly ( $\geq 75$ years) patients with end-stage renal disease (ESRD) has increased markedly, including in the Limousin region, which has the oldest population in France. We retrospectively compared outcomes in elderly and non-elderly ESRD patients who started dialysis during two time periods.

Methods: Baseline clinical characteristics, care, and survival rates were assessed in 557 ESRD patients aged $\geq 75$ and $<75$ years who started dialysis in 2002-2004 and 2005-2007. Survival curves and Cox proportional hazards model were used to assess survival and factors associated with survival.

Results: Of the 557 patients, 343 and 214 were $<75$ years and $\geq 75$ years, respectively. Dialysis was started in 2002-2004 and 2005-2007 by 197 and 146 patients <75 years, respectively, and by 96 and 118 patients $\geq 75$ years, respectively. Median age (73.4 years [interquartile range [IQR] 61.7-79.5 years] vs 69.5 years [IQR 57.4-77.4 years] $p=0.001$ ) and the proportion aged $\geq 75$ years $(44.7 \%$ vs $32.8 \%, p=0.004)$ were significantly higher in $2005-2007$ than in 2002-2004. Improved initial status during 2005-2007 was observed only in patients $\geq 75$ years, with a decrease in some co-morbidities, improved walking and better preparation for dialysis. Mortality rates were significantly lower in 2005-2007 than in 2002-2004 (hazard ratio 0.81, 95\% confidence interval 0.69-0.95; $p=0.008$ ), with the difference due to factors associated with clinical status and care.
\end{abstract}

Conclusions: Improved initial clinical status and better preparation for dialysis, accompanied by increased survival, were observed for patients $\geq 75$ years who started dialysis more recently, perhaps because of early referral to a nephrologist.

Keywords: Co-morbidity, Elderly, End stage renal disease, Outcome, Survival

\section{Background}

Over the past 10 years, all countries in Europe have experienced increases in the rate of elderly people beginning dialysis [1,2]. For example, $37.9 \%$ of patients in France who started dialysis in 2009 were older than 75 years [3]. Identifying the characteristics of this elderly population is important in adapting policies for appropriate care and in estimating future needs by renal care organisation. The higher incidence of end-stage renal disease (ESRD) may be due in large part to the ageing of the general population and the broader access to dialysis

\footnotetext{
* Correspondence: florence.glaudet@unilim.fr

'Nephrology Unit, Limoges University Hospital, Limoges, France

Full list of author information is available at the end of the article
}

therapy among older persons with renal failure $[4,5]$. Multivariate analysis has shown that increasing age is significantly predictive of survival in elderly patients on dialysis [6-9]. Other studies have shown that the excess mortality observed in people on dialysis compared with the general population was less apparent in older than in younger patients $[10,11]$.

Limited data are available on age-related differences in the clinical status of patients on dialysis and their trends over time. A study comparing differences between countries in haemodialysis patients according to age observed country-related differences in management practices of elderly individuals, but did not assess changes in management practices over time [12].

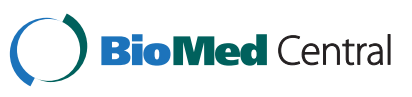


Limousin is a region in France included in the "REIN" registry, which provides quality controlled data about patients with ESRD. In 2010, 44.3\% of individuals on dialysis in Limousin were over 75 years old, compared with $39.2 \%$ of individuals throughout the rest of France. To assess the impacts of age and management practices over time in patients with ESRD, we analysed the baseline clinical characteristics and care of all patients, aged $<75$ and $\geq 75$ years, who started dialysis between in 2002-2004 and 2005-2007. Survival on dialysis was compared in patients who started dialysis in these two time periods, and factors associated with improved survival in elderly patients were analysed.

\section{Methods}

\section{Population}

The population of Limousin consisted of 718,716 residents in 2002 and 737,001 in 2007. All patients living in the Limousin region and who had started long-term dialysis between January 1, 2002, and December 31, 2007 were included in the study. These 557 patients were divided into four groups, by age ( $<75$ and $\geq 75$ years) and period starting dialysis (2002-2004 and 2005-2007). Treatment modalities for haemodialysis included three haemodialysis centres located in health facilities with physicians always available (in-centre haemodialysis), three haemodialysis centres without a physician always available (outcentre haemodialysis), three self-care units and home haemodialysis. Peritoneal dialysis (PD) was either continuous ambulatory or automated.

\section{Data source}

The REIN design has been described in detail [13]. The data included in this study were released from the REIN registry data under the responsibility of the authors, and with the approval of the Regional Committee in Limousin. Data gathered for this study included patient demographics, co-morbidities, severe disability, mobility, nutritional status, renal function, anaemia status, and dialysis modality. Primary renal diseases and renal biopsy before dialysis were included. The eight co-morbidities assessed were diabetes, chronic respiratory disease, heart failure, cerebrovascular disease, peripheral vascular disease, arrhythmia, coronary vascular disease and active malignancy. The two vascular risk factors analysed were hypertension and smoker/ex-smoker.

Handicaps included severe disabilities (severely impaired vision, amputation, hemiplegia and paraplegia) and severe behavioural disorders (dementia, psychosis, and severe neurosis that may affect patient dependence or compliance with treatment). Mobility was classified into three groups according to patient dependence. Serum albumin concentrations were measured and body mass index (BMI) was calculated as weight $(\mathrm{kg}) /$ square of height $(\mathrm{m})$. Data on mobility and BMI were missing for $<5 \%$ of patients.

An urgent first dialysis was defined as its immediate performance after evaluation by a nephrologist due to risk of vital status, poorly tolerated anaemia, pericarditis or uremic confusion of origin.

Renal function was assessed as estimated glomerular filtration rate (eGFR), which was calculated using the modification of diet in renal disease (MDRD) formula. Pre-dialysis anaemia and first treatment modalities were also determined.

\section{Outcome}

All patients were monitored for 4 years after their first dialysis. Major events included renal transplantation, changes in place of dialysis, transient recovery of renal function and death. Vital status was checked monthly, so that event records can be considered exhaustive.

\section{Statistical analysis}

The annual incidence rates were age-standardized using as reference the estimate of the metropolitan French population for each year considered.

The impact of demographic factors, age structure and renal disease risk on ESRD incidence was analysed using the RiskDiff web tool [14], established as described [15].

Patients' baseline characteristics were compared using the chi-square test and Student's t-test.

In analysing survival, patients were censored if they underwent renal transplantation during the follow-up period or were still alive and on dialysis at the end of follow-up. The chi-square test was used to compare the proportion of deaths four years after the start of dialysis. Four-year survival analysis consisted of three steps. First, the Kaplan-Meier method was used to estimate patient survival by stratum (age group and study period), with survival curves compared using log rank tests. Age groups showing significantly different mortality outcomes during the two treatment times were analysed for factors associated with this difference. Thus, in the second step for this group, a Cox proportional hazard model was used to analyse risk factors associated with death during the first 48 months (univariate analysis), regardless of the dialysis initiation period. Finally, in order to analyse the association between study period and mortality, five Cox proportional hazard models were fitted with sequential adjustments for confounding variables (multivariate analysis). Model-1 was adjusted for age and gender; Model-2 was Model-1 plus adjustments for co-morbidities associated with survival during the previous step; Model-3 was Model-1 plus adjustments for mobility; model- 4 was Model-1 plus adjustments for initial condition at the start of dialysis; and Model 5 included all variables used in the other models. 
Hazard ratios [HRs] and their 95\% confidence intervals [CIs] were calculated. All data were analysed using JMP 6 (SAS Institute, Cary, NC). A p-value $<0.05$ was defined as statistically significant.

\section{Results}

\section{Baseline characteristics}

During the study period, 557 patients underwent dialysis, including 293 in 2002-2004 and 264 in 2005-2007. Of the patients who started dialysis in 2002-2004, 197 were $<75$ and 96 were $\geq 75$ years old; In 2005-2007, 146 were $<75$ and 118 were $\geq 75$ years old. Median age of cohorts were 69.5 years [IQR 57.4-77.4 years] in 20022004 and 73.4 years [IQR 61.7-79.5 years] in 2005-2007 $(\mathrm{p}=0.001)$. Among the patients $\geq 75$ years old, median age was 79.9 years [IQR 77.5-82.9 years] in 20022004 and 80.3 years [IQR 77.4-83.3 years] in 2005-2007 $(\mathrm{p}=\mathrm{NS})$.

Figure 1 shows the change in incidence by age group. The older age group showed an increase in incidence of ESRD between 2003 and 2007, especially after 2006. The incidence was high (385 per million [IQR 254-516 per million]) in 2002-2004, but was even higher (437 per million [IQR 301-573 per million] in 2005-2007). The incidence of ESRD in patients $\geq 75$ years increased from 397 per million [IQR $262-532$ per million] in 20022004 to 457 per million [IQR $313-597$ per million] in 2005-2007.

Figure 2 shows the real contribution of kidney disease to the change in ESRD incidence over time, taking into account changes in the general population between 2002 and 2007. The increased incidence in ESRD for patients $\geq 75$ years between 2003 and 2007 was associated with an increase in the proportion of the elderly population, but primarily to the increase in kidney disease risk. In the younger population, those aged $<75$ years, the decreased incidence of ESRD was due mainly to a lower risk of kidney disease.

Table 1 shows the baseline characteristics of patients. In patients aged $<75$ years, the percentages with

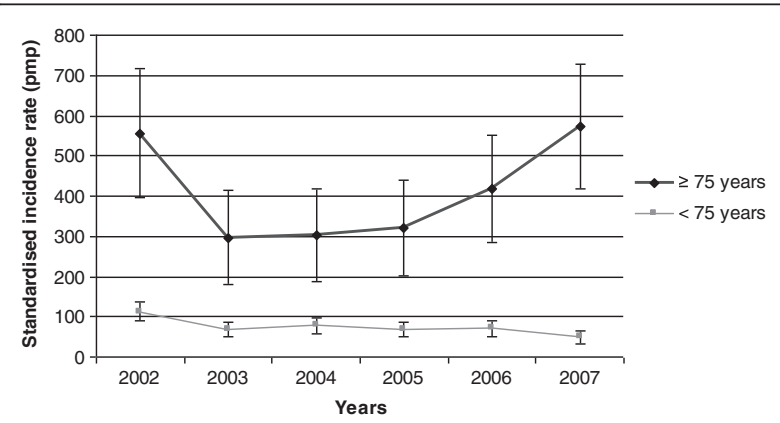

Figure 1 Standardized incidence by age group between 2002 and 2007. cerebrovascular disease, peripheral vascular disease and arrhythmia were significantly higher in 2005-2007 than in 2002-2004. The percentage of patients aged $<44$ years was lower in 2005-2007. When only patients aged $45-74$ years were assessed, there were also significant increases over time in these three co-morbidities. The first treatment modality has changed significantly over time, with a decrease in the number of patients undergoing peritoneal dialysis and an increase in those undergoing haemodialysis with fistula (Table 2).

When we assessed patients aged $\geq 75$ years, we observed no significant difference in co-morbidities over time, although the proportions with diabetes, heart failure and arrhythmia decreased. The percentage of patients walking independently was higher in 2005-2007 than in 20022004 ( $p=0.002)$. More biopsies were performed and more patients on dialysis had a serum albumin concentration $\geq 35 \mathrm{~g} / \mathrm{l}$ during 2005-2007. The proportions of patients on dialysis with a baseline eGFR $<10 \mathrm{ml} / \mathrm{min} /$ $1.73 \mathrm{~m}^{2}$ and with haemoglobin concentrations $<11 \mathrm{~g} / \mathrm{dl}$ were significantly higher during the second period.

The interaction between age and study period was tested for all baseline characteristics ( $\mathrm{p} 3$ of Table 1). This interaction was significant for renal biopsy, arrhythmia, and haemoglobin concentrations.

\section{Patient survival}

After 4 years of follow-up, 79 (82.3\%) and 77 (65.2\%) patients aged $\geq 75$ years died in 2002-2004 and 20052007 , respectively $(\mathrm{p}=0.033)$. Only one underwent renal transplantation during follow-up. Among patients aged $<75$ years, $59(29.9 \%)$ and $54(37.0 \%)$ died within 4 years in 2002-2004 and 2005-2007, respectively. Fiftyeight patients (29.4\%) underwent renal transplantation in $2002-2004$ and $37(25.3 \%)$ in 2005-2007 ( $=0.378)$.

The Kaplan-Meier survival curves are shown in Figure 3. Median survival was stable in the entire cohort (3.7 years in 2002-2004 and 3.6 years in 2005-2007) and in patients $<75$ years old $(\mathrm{p}=0.285)$. In patients aged $\geq 75$ years, however, median survival was significantly longer in 20052007 than in 2002-2004 (2.6 vs 1.6 years, $\mathrm{p}=0.008$ ).

\section{Factors associated with survival in patients $\geq 75$ years}

As a survival difference was observed only for patients aged $\geq 75$ years, we analysed factors potentially involved in improved survival of this group. Univariate analyses showed that period of dialysis initiation, primary kidney disease, diabetes, heart failure, impaired mobility, estimated glomerular filtration rate (eGFR) and first treatment modality were significantly associated with mortality.

Patients who started dialysis in 2005-2007 had a 19\% lower risk of dying after 4 years (HR 0.81, CI 95\% 0.70.9). Adjustment for co-morbidities resulted in a decreased risk of $15 \%$, which remained statistically significant. There 


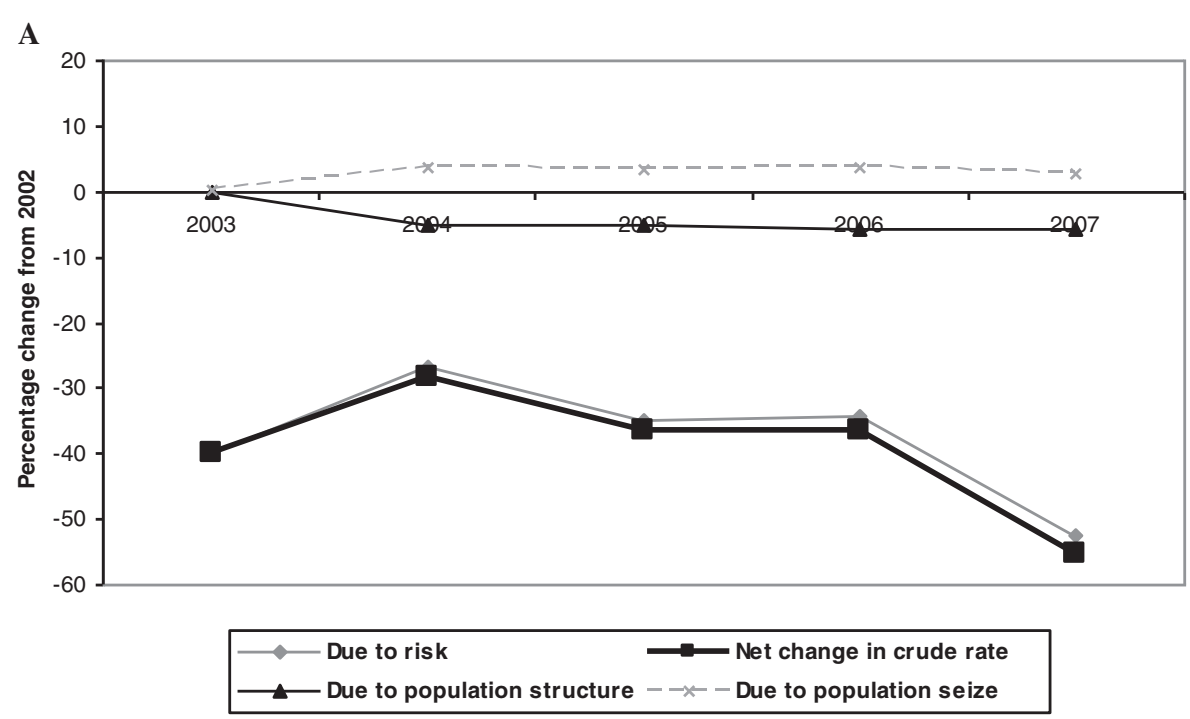

B

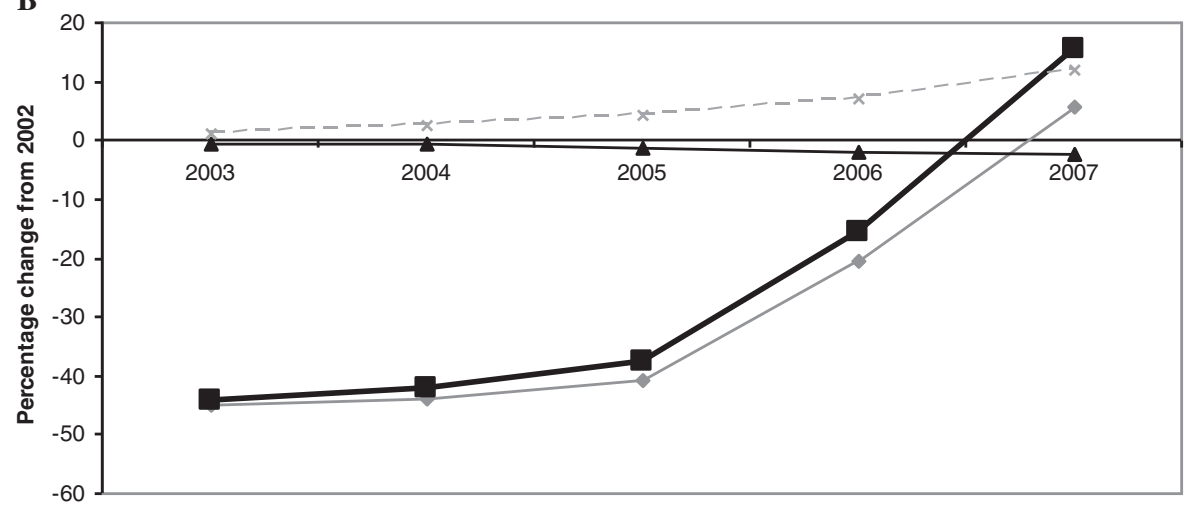

Figure 2 Differences in incidence from 2003 to 2007 compared to the baseline year 2002. Legend of Figure 2: A. $<75$ years; B. $\geq 75$ years.

was no difference in fully adjusted mortality after introducing mobility (Model 3) or initial treatment condition (Model 4). Model 5 showed that heart failure, assistance needed for transfers, PD, and eGFR $\geq 10 \mathrm{ml} / \mathrm{min} / 1.73 \mathrm{~m}^{2}$ were significantly associated with the better survival observed in 2005-2007 (Table 3).

\section{Discussion}

This study showed that the percentage of patients $\geq 75$ years of age starting dialysis increased and that their initial clinical characteristics improved over time, improvements associated with significantly longer survival.

\section{Increases in elderly population}

Over the past 10 years, the number of elderly patients starting dialysis has increased in many countries $[1,6,10,16-18]$. Our results confirm that the dialysed population in Limousin has increased in age. Several methods of calculation showed that 2002 remained an exception to the steady increase in the incidence of elderly persons starting dialysis, suggesting that the higher number of patients observed was probably due to sample fluctuations.

Many hypotheses have attempted to explain the significant increase in the incidence of elderly patients starting dialysis. The first hypothesis was an increase in the incidence of diabetes [4,5] and the improved survival from non renal diseases among people with chronic renal insufficiency $[19,20]$. Higher eGFR and wider access to dialysis were shown associated with the dramatic increases in incidence of older patients [18] and of patients of all ages [21] starting dialysis. We observed no difference in the proportion of patients $\geq 75$ years with eGFR $\geq 10 \mathrm{ml} / \mathrm{min} / 1.73 \mathrm{~m}^{2}$ in the two time periods, indicating that this factor cannot explain the increase in ESRD incidence among elderly people in Limousin. Improved patient care, including early referral to nephrologists prior to dialysis, may be associated with the increased incidence of elderly subjects starting dialysis, by reducing death before ESRD. Indeed, the increased proportions of our patients with fistula before dialysis and better clinical status strengthen this hypothesis. 
Table 1 Patient clinical baseline characteristics at dialysis initiation according to age and period

\begin{tabular}{|c|c|c|c|c|c|c|c|}
\hline & \multicolumn{3}{|c|}{$<75 \mathrm{yr}$} & \multicolumn{3}{|c|}{$\geq 75 \mathrm{yr}$} & \multirow{4}{*}{ P3 } \\
\hline & 2002-2004 & $2005-2007$ & P1 & 2002-2004 & $2005-2007$ & P2 & \\
\hline & $(n=197)$ & $(n=146)$ & & $(n=96)$ & $(n=118)$ & & \\
\hline & $\%$ & $\%$ & & $\%$ & $\%$ & & \\
\hline Age & & & 0.05 & & & NS & \\
\hline $0-19$ & $3(1.5)$ & $1(0.7)$ & & & & & \\
\hline $20-44$ & $31(15.7)$ & $11(7.5)$ & & & & & \\
\hline $45-64$ & $71(36.0)$ & $68(46.6)$ & & & & & \\
\hline $65-74$ & $92(46.7)$ & $66(45.2)$ & & & & & \\
\hline $75-84$ & & & & $81(84.4)$ & 99(83.9) & & \\
\hline 85 et + & & & & 15(15.6) & 19(16.1) & & \\
\hline \multicolumn{8}{|l|}{ Gender } \\
\hline Men & $126(64.0)$ & $100(68.5)$ & & $54(56.2)$ & $83(70.3)$ & & \\
\hline Women & $71(36.0)$ & $46(31.5)$ & & $42(43.7)$ & $35(29.7)$ & & \\
\hline Primary rental disease & & & NS & & & 0.10 & NS \\
\hline Glomerulonephritis & $38(19.3)$ & 24(16.4) & & $9(9.4)$ & 20(16.9) & & \\
\hline Diabetic nephropathy & $45(22.8)$ & $34(23.3)$ & & 19(19.8) & $15(12.7)$ & & \\
\hline Cystic nephropathy & $14(7.1)$ & 17(11.6) & & $2(2.1)$ & $2(1.7)$ & & \\
\hline Tubular-Interstitial nephropathy & 19(9.6) & $12(8.2)$ & & $4(4.2)$ & $8(6.8)$ & & \\
\hline Vascular nephropathy & $36(18.3)$ & $20(13.7)$ & & $37(38.5)$ & $51(43.2)$ & & \\
\hline Unknown & $29(14.7)$ & $25(17.1)$ & & $23(24.0)$ & $15(12.7)$ & & \\
\hline Other & $16(8.1)$ & 14(9.6) & & $2(2.1)$ & $7(5.9)$ & & \\
\hline Renal biopsy & $43(21.8)$ & $31(21.2)$ & NS & $4(4.2)$ & 14(11.9) & $0.044^{*}$ & $0.047^{*}$ \\
\hline \multicolumn{8}{|l|}{ Co-morbidities } \\
\hline Diabetes & $65(33.0)$ & $54(37.0)$ & NS & $39(40.6)$ & $34(28.8)$ & 0.07 & 0.06 \\
\hline Chronic respiratory disease & $15(7.6)$ & 17(11.6) & NS & $11(11.5)$ & 14(11.9) & NS & NS \\
\hline Heart failure & $40(20.3)$ & 28(19.2) & NS & $42(43.7)$ & $37(31.4)$ & 0.06 & NS \\
\hline Cerebrovascular disease & $10(5.1)$ & 18(12.3) & $0.016^{*}$ & 13(13.5) & 16(13.6) & NS & 0.09 \\
\hline Peripheral vascular disease & $28(14.2)$ & $37(25.3)$ & $0.010^{*}$ & $26(27.1)$ & $31(26.3)$ & NS & 0.07 \\
\hline Arrhythmia & $22(11.2)$ & $31(21.2)$ & $0.011^{*}$ & $29(30.2)$ & $29(24.6)$ & NS & 0.015 \\
\hline Coronary vascular disease & $40(20.3)$ & $33(22.6)$ & NS & $35(36.5)$ & $42(35.6)$ & NS & NS \\
\hline Active malignancy & $9(4.6)$ & $12(8.2)$ & NS & $7(7.3)$ & $10(8.5)$ & NS & NS \\
\hline \multicolumn{8}{|l|}{ Risk factors } \\
\hline History of hypertension & 148(75.1) & 118(80.8) & NS & $75(78.1)$ & $101(85.6)$ & NS & NS \\
\hline Smoker/Ex-smoker & $71(36.0)$ & $69(47.3)$ & NS & $31(32.3)$ & $45(38.1)$ & NS & NS \\
\hline Handicap ${ }^{7}$ & $23(11.7)$ & 19(13.0) & NS & $6(6.2)$ & $9(7.6)$ & NS & NS \\
\hline Mobility & & & NS & & & $0.002^{*}$ & NS \\
\hline Walk without help & 169(88.5) & 130(90.9) & & $57(63.3)$ & 88(75.9) & & \\
\hline Need assistance for transfers & 15(7.9) & $6(4.2)$ & & $31(34.4)$ & $18(15.5)$ & & \\
\hline Totally dependent for transfers & $7(3.7)$ & $7(4.9)$ & & $2(2.2)$ & $10(8.6)$ & & \\
\hline
\end{tabular}

P1. P-value $<75$ years (2002-2004 vs 2005-2007).

P2. $P$-value $\geq 75$ years (2002-2004 vs $2005-2007)$.

P3. P-value Age $x$ Period.

${ }^{1}$ including severe disability (vision impairment, paraplegia, hemiplegia, and amputation) and severe behaviour disorders (dementia, psychosis or severe neurosis). NS Not Significant (with $p>0.1$ ).

Improvements in pre-dialysis monitoring can lead not only to patients starting dialysis at a later age, but also to improvements in their general condition and a lower eGFR before starting dialysis. Presumably, some patients who would not have survived before reaching ESRD would now survive and be candidates for dialysis.

The urgency of the first dialysis did not differ between the two time periods, regardless of age, and did not 
Table 2 Biological baseline characteristics and conditions of dialysis initiation according to age and period

\begin{tabular}{|c|c|c|c|c|c|c|c|}
\hline & \multicolumn{3}{|c|}{$<75 \mathrm{yr}$} & \multicolumn{3}{|c|}{$\geq 75 \mathrm{yr}$} & \multirow{3}{*}{ P3 } \\
\hline & $2002-2004$ & $2005-2007$ & P1 & $2002-2004$ & $2005-2007$ & P2 & \\
\hline & $(n=197)$ & $(n=146)$ & & $(n=96)$ & $(n=118)$ & & \\
\hline Serum albumin & & & NS & & & $0.027^{*}$ & NS \\
\hline$<35 \mathrm{~g} / \mathrm{l}$ & 63(32.0) & $51(34.9)$ & & $44(45.8)$ & $50(42.4)$ & & \\
\hline$\geq 35 \mathrm{~g} / \mathrm{l}$ & $78(39.6)$ & $61(41.8)$ & & $21(21.9)$ & $44(37.3)$ & & \\
\hline Missing & $56(28.4)$ & $34(23.3)$ & & $31(32.3)$ & $24(20.3)$ & & \\
\hline Body mass index & & & NS & & & NS & NS \\
\hline$<18,5 \mathrm{~kg} / \mathrm{m}^{2}$ & $9(4.7)$ & $5(3.6)$ & & $2(2.3)$ & $7(6.1)$ & & \\
\hline $18,5-25 \mathrm{~kg} / \mathrm{m}^{2}$ & $98(51.0)$ & $67(47.9)$ & & $51(60.0)$ & $64(56.1)$ & & \\
\hline$\geq 18,5 \mathrm{~kg} / \mathrm{m}^{2}$ & $85(44.3)$ & $68(48.6)$ & & $32(37.6)$ & $43(37.7)$ & & \\
\hline Baseline eGFR & & & NS & & & $0.047^{*}$ & 0.08 \\
\hline$<7 \mathrm{ml} / \mathrm{min} / 1.73 \mathrm{~m}^{2}$ & $103(52,3)$ & $59(40,4)$ & & $31(32,3)$ & $46(39,0)$ & & \\
\hline $7-10 \mathrm{ml} / \mathrm{min} / 1.73 \mathrm{~m}^{2}$ & $47(23,9)$ & $46(31,5)$ & & $26(27,1)$ & $38(32,2)$ & & \\
\hline$\geq 10 \mathrm{ml} / \mathrm{min} / 1.73 \mathrm{~m}^{2}$ & $32(16.2)$ & $32(21.9)$ & & $28(29.2)$ & $31(26.3)$ & & \\
\hline Missing & $15(7.6)$ & $9(6.2)$ & & 11(11.5) & $3(2.5)$ & & \\
\hline \multicolumn{8}{|l|}{ Pre-dialysis anemia care } \\
\hline Hemoglobin & & & NS & & & $<0.001^{*}$ & $0.005^{*}$ \\
\hline$<11 \mathrm{~g} / \mathrm{dl}$ & $112(56.9)$ & 77(52.7) & & $42(43.7)$ & $74(62.7)$ & & \\
\hline$\geq 11 \mathrm{~g} / \mathrm{dl}$ & 63(32.0) & $57(39.0)$ & & $3637.5)$ & $41(34.7)$ & & \\
\hline Missing & $22(11.2)$ & $12(8.2)$ & & $18(18.7)$ & $3(2.5)$ & & \\
\hline Pre-dialysis ESA treatment & 93(47.2) & $85(57.8)$ & $0.044^{*}$ & $51(53.1)$ & $67(56.8)$ & NS & NS \\
\hline First treatment modality & & & $0.004^{*}$ & & & NS & NS \\
\hline Peritoneal dialysis & 39(19.8) & 17(11.6) & & $35(36.5)$ & $32(27.1)$ & & \\
\hline Hemodialysis with fistula & $77(39.1)$ & 74(50.7) & & 18(18.7) & $36(30.5)$ & & \\
\hline Hemodialysis without fistula & $81(41.1)$ & $55(37.7)$ & & $43(44.8)$ & $50(42.4)$ & & \\
\hline In urgency & 39(19.8) & 25(17.1) & NS & $16(16.7)$ & $19(16.1)$ & NS & NS \\
\hline
\end{tabular}

P1. $P$-value $<75$ years (2002-2004 vs 2005-2007).

P2. $P$-value $\geq 75$ years (2002-2004 vs 2005-2007).

P3. P-value Age x Period.

eGFR Estimated glomerular filtration rate, ESA erythropoietin-stimulating agent, NS Not Significant (with $p>0.1$ ).

affect survival. This variable therefore did not provide information on nephrological follow-up prior to the start of dialysis.

\section{Progression over time}

We also observed changes in clinical status and patient care between the two periods. The percentage of elderly patients undergoing renal biopsies increased significantly, resulting in a decreased in the rate of patients with indeterminate renal diseases and indicating that the management of this population changed before the start of dialysis. There was a correlation between age and the start of dialysis, indicating an increase in work-ups at the beginning of dialysis.

Disability among older patients was modified over time, with older patients having improved autonomy and the percentage walking without help increasing significantly. Although nutritional status may difficult to determine only from measurements of serum albumin concentration, the rate of albuminemia decreased, suggesting improvements in nutritional status and/or inflammatory responses. This finding is consistent with previous results, which underlined the importance of monitoring albumin concentration [22]. In contrast, pre-dialysis anemia care became worse for patients over time, a finding consistent with international recommendations of a lower target haemoglobin concentration, resulting from findings suggesting that administration of high EPO does not reduce mortality or cardiovascular risk prior to the initiation of dialysis $[23,24]$.

Although a higher BMI is associated with worsening co-morbidities in younger Caucasian populations, this was less evident in older patients [25]. In our study, this was difficult to determine, inasmuch as only 2 patients $\geq 75$ years old had a BMI $<18.5 \mathrm{~kg} / \mathrm{m}^{2}$ in $2002-2004$.

The increase in the percentage of patients undergoing initial haemodialysis with fistula was partly due to a decrease in haemodialysis without fistula, but was also to a 


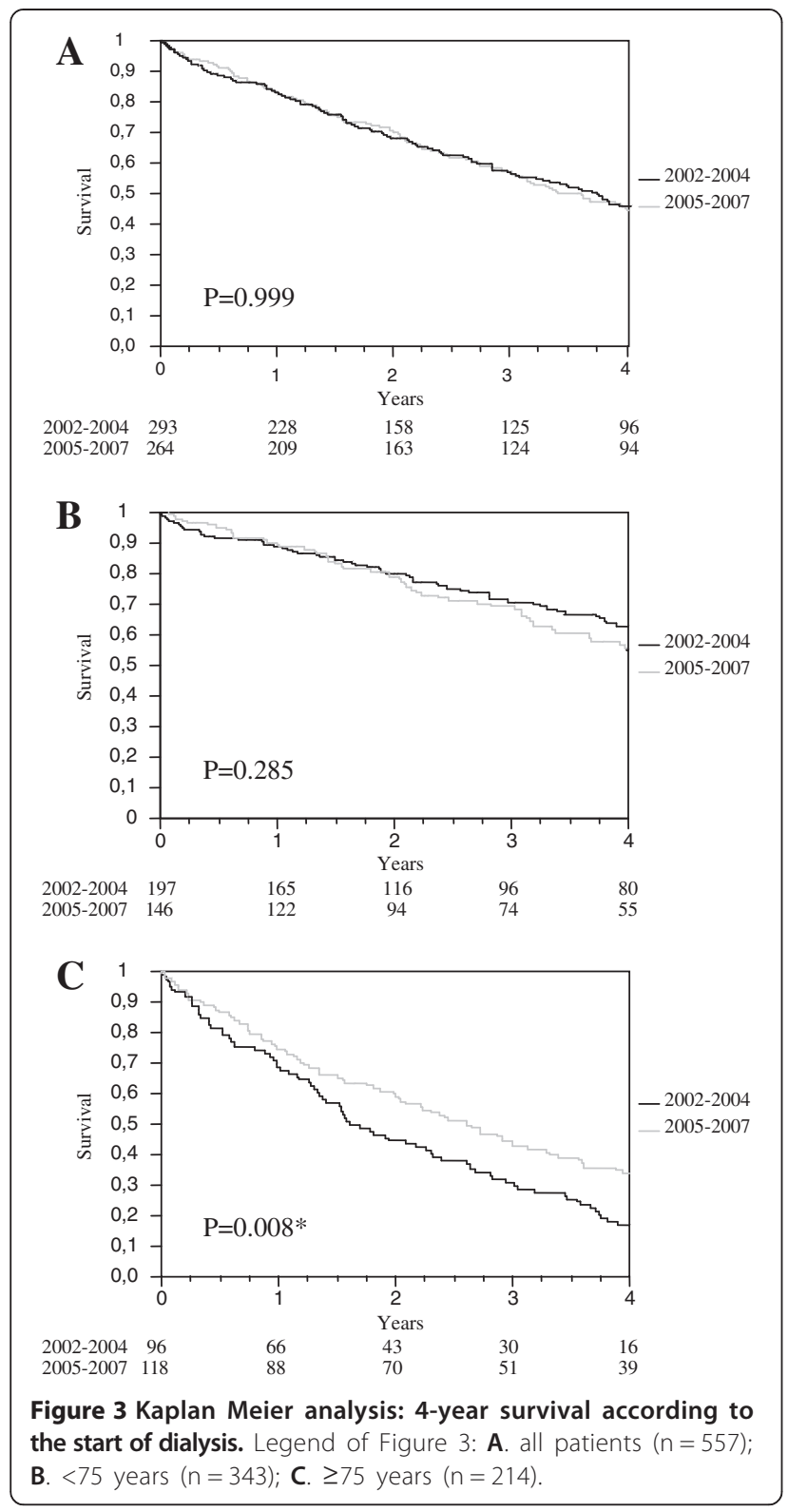

decrease in first-line treatment of patients by PD. This difference was significant only for patients $<75$ years old.

\section{Survival}

The main finding of our study was the improvement in survival of elderly patients over time. In contrast, there were no significant differences in the entire cohort or the younger patient group between the two periods. Age has been reported to influence survival in dialysed elderly patients $[7,18,26]$, although other studies $[10,11,27]$ have found that age was not an independent predictor of survival in elderly patients. A method of predicting 6-month prognosis in elderly patients starting dialysis found that functional limitations were better predictors than age [27]. When this score was applied to our cohort, the mortality rates were similar to those presented, at least for groups containing large numbers of patients (data not shown). Thus, our results were in agreement with studies showing that neither age nor gender was significantly associated with survival among elderly patients. Moreover, our findings emphasize the importance of functional limitations in predicting survival. Improved autonomy, including being able to walk unaided, was significantly associated with the increase in survival over time. Walking has already been found to be strongly associated with mortality in aged populations, a relationship not altered by dialysis $[17,28]$.

The impact of the method of dialysis on survival is unclear. Although studies have analysed the link between dialysis methods and survival $[17,26,29]$, those studies were criticized due to the selection bias inherent in the choice of dialysis method, which could explain apparent differences in mortality rate [30]. Indeed, peritoneal dialysis is often promoted for patients with diabetes [31], elderly patients [32] and patients with heart failure [33]. Although this requires further investigation, evaluating the impact of dialysis method on survival is very difficult, with the method adjusted for individual patients.

The main limitation of this study was its sample size. Although Limousin has the highest proportion of people over 75 years old in France, it is one of the least populated regions. Thus, some variables with borderline significance may be more sensitive to adjustments. Another limitation was that our study included only ESRD patients starting dialysis, excluding a small number of patients with serious ESRD who were treated conservatively and introducing a selection bias. Following the evolution of this population over time seems to be important. As in many regions of France, a system monitoring early renal failure was recently initiated in Limousin. Nephrological follow up before dialysis has an impact on quality of life. In the elderly, the quality of life is better when the first dialysis has been programmed [34]. Finally, we compared patient survival with data at the initiation of dialysis. Changes in patient co-morbidities and their care after dialysis initiation were not considered.

This study also has several strengths. The small number of nephrologists and their involvement during the pilot phase of the registry ensured stability in coding and completeness and resulted in rigorous patient follow up. Thus, our cohort was not subject to the bias frequently observed in larger cohorts, due to the exclusion of patients with missing data or difficult compilation from various sources of information.

\section{Conclusions}

In conclusion, we observe an increase over time in the incidence of elderly patients starting dialysis, as well as a 
Table 3 Adjusted hazard ratios of overall, 4-year mortality associated with study period (for all 214 patients over 75 years)

\begin{tabular}{|c|c|c|c|c|c|c|c|c|c|c|c|c|c|c|c|}
\hline & \multicolumn{3}{|c|}{ Model-1 } & \multicolumn{3}{|c|}{ Mdel-2 } & \multicolumn{3}{|c|}{ Model-3 } & \multicolumn{3}{|c|}{ Model-4 } & \multicolumn{3}{|c|}{ Model-5 } \\
\hline & \multicolumn{3}{|c|}{ Demographics } & \multicolumn{3}{|c|}{ Demographics + Comorbidity } & \multicolumn{3}{|c|}{$\overline{\text { Demographics + Mobility }}$} & \multicolumn{3}{|c|}{ Demographics + Care } & \multicolumn{3}{|c|}{$1+2+3+4$} \\
\hline & HR & $95 \% \mathrm{Cl}$ & $p$ & HR & $95 \% \mathrm{Cl}$ & $\mathrm{p}$ & HR & $95 \% \mathrm{Cl}$ & $\mathrm{p}$ & HR & $95 \% \mathrm{Cl}$ & $p$ & HR & $95 \% \mathrm{Cl}$ & $p$ \\
\hline Dialysis initiation year. reference: & $2002-2004$ & & & & & & & & & & & & & & \\
\hline $2005-2007$ & 0.81 & $0.69-0.95$ & $0.010^{*}$ & 0.85 & $0.72-0,999$ & $0.049^{*}$ & 0.88 & $0.74-1.06$ & NS & 0.85 & $0.72-1.00$ & 0.052 & 0.94 & $0.78-1.13$ & NS \\
\hline \multicolumn{16}{|l|}{ Age. reference: 75-84 years } \\
\hline$\geq 85$ years & 1.22 & $0.99-1.48$ & 0.06 & 1.27 & $1.03-1.54$ & $0.027^{*}$ & 1.18 & $0.95-1.44$ & NS & 1.20 & $0.97-1.46$ & 0.09 & 1.21 & $0.97-1.48$ & 0.09 \\
\hline \multicolumn{16}{|l|}{ Gender. reference: Male } \\
\hline Female & 0.99 & $0.84-1.17$ & NS & 1.00 & $0.84-1.18$ & NS & 0.95 & $0.80-1.13$ & NS & 0.97 & $0.81-1.15$ & NS & 0.96 & $0.80-1.15$ & NS \\
\hline \multicolumn{16}{|c|}{ Comobidities. reference: without this comorbidity } \\
\hline Heart failure & & & & 1.31 & $1.11-1.55$ & $0.001^{*}$ & & & & & & & 1.23 & $1.04-1.46$ & $0.018^{*}$ \\
\hline Diabetes & & & & 1.21 & $1.02-1.43$ & $0.030^{*}$ & & & & & & & 1.12 & $0.94-1.93$ & 0.10 \\
\hline \multicolumn{16}{|l|}{ Mobility. reference: walk out help } \\
\hline Need assistance for transfers & & & & & & & 1.43 & $1.16-1.74$ & $<0.001 *$ & & & & 1.40 & $1.13-1.71$ & $0.002^{*}$ \\
\hline Tatally dependent for transfers & & & & & & & 1.42 & $0.97-1.96$ & 0.07 & & & & 1.38 & $0.94-1.93$ & 0.10 \\
\hline \multicolumn{16}{|c|}{ Dailysis modality. reference: HD with fistula } \\
\hline HD without fistula & & & & & & & & & & 1.29 & $1.03-1.62$ & $0.025^{*}$ & 1.16 & $0.92-1.48$ & NS \\
\hline PD & & & & & & & & & & 1.49 & $1.19-1.89$ & $<0.001^{*}$ & 1.38 & $1.09-1.76$ & $0.008^{*}$ \\
\hline \multicolumn{16}{|c|}{ Baseline eGFR. reference: $7 \geq e G F R<10 \mathrm{~m} / / \mathrm{min} / 1.73 \mathrm{~m}^{2}$} \\
\hline $\mathrm{eGFR}<7 \mathrm{ml} / \mathrm{min} / 1.73 \mathrm{~m}^{2}$ & & & & & & & & & & 1.08 & $0.88-1.33$ & NS & 1.18 & $0.95-1.46$ & NS \\
\hline eGFR $\geq 10 \mathrm{ml} / \mathrm{min} / 1.73 \mathrm{~m}^{2}$ & & & & & & & & & & 1.25 & $1.00-1.56$ & $0.047^{*}$ & 1.36 & $1.08-1.71$ & 0.009 \\
\hline Missing & & & & & & & & & & 1.13 & $0.79-1.55$ & NS & 1.12 & $0.77-1.57$ & NS \\
\hline
\end{tabular}

HD hemodialysis, $P D$ peritoneal dialysis, eGFR estimated glomerular filtration rate, $H R$ hazard ratio, $95 \% \mathrm{Cl} 95 \%$ confidence intervals.

Model-1 was adjusted for age and gender.

Model-2 was adjusted as Model-1 + heart failure and diabetes.

Model-3 was adjusted as Model-1 + mobility.

Model-4 was adjusted as Model-1 + dialysis modality and baseline eGFR.

Model- 5 was adjusted for all variables in previous models.

NS Not Significant (with $p>0.1$ ) 
decrease in the differences between younger and elderly patients. Both of these findings may be due to global improvements in the health status of elderly individuals. The decrease in some co-morbidities and improvements in functional limitations were associated with significantly improved survival among patients $\geq 75$ years. Our findings suggest that older individuals are better managed during the progression of chronic kidney disease, a finding requiring confirmed in other cohorts of patients with chronic kidney disease.

\section{Competing interests}

The authors declare that they have no competing interests.

\section{Authors' contributions}

FG conceived of the study, performed the statistical analysis and drafted the manuscript. $C H$, JA, VA, FB, RB, BC, JPC, MC, ZD, ME, PH, CL, CL, MM, PP, JMP, $J P R$, and MR checked and validated data and helped to draft the manuscript. CC participated in the statistical analysis and helped to draft the manuscript. JCA participated in its design and coordination and helped to draft the manuscript. All authors read and approved the final manuscript.

\section{Acknowledgments}

We acknowledge all those who participated in the collection and monitoring of the completeness of the registry, especially the secretaries of the dialysis centres. We also thank Mathilde Lassalle, Jeanne Moreau and Bénédicte Stengel for their help in preparing this manuscript.

\section{Author details}

${ }^{1}$ Nephrology Unit, Limoges University Hospital, Limoges, France. ${ }^{2}$ ALURAD (Limousine Association for the use of the artificial kidney at home, Limoges, France. ${ }^{3}$ Nephrology Unit, Brive Hospital, Brive, France. ${ }^{4}$ ALURAD (Limousine Association for the use of the artificial kidney at home, Brive, France. ${ }^{5}$ REIN registry, Biomedecine Agency, La Pleine-Saint Denis, France.

\section{Received: 27 November 2012 Accepted: 5 June 2013}

Published: 25 June 2013

\section{References}

1. Stengel B, Billon S, Van Dijk PC, Jager KJ, Dekker FW, Simpson K, Briggs JD: Trends in the incidence of renal replacement therapy for end-stage renal disease in Europe, 1990-1999. Nephrol Dial Transplant 2003, 18(9):1824-1833.

2. Stel VS, van de Luijtgaarden MW, Wanner C, Jager KJ: The 2008 ERA-EDTA Registry Annual Report-a precis. NDT Plus 2011, 4(1):1-13.

3. Couchoud C, Lassalle M, Stengel B, Jacquelinet C: Renal epidemiology and information network: 2009 annual report. Nephrol Ther 2011, 7(Suppl 2):S41-S214.

4. Muntner P, Coresh J, Powe NR, Klag MJ: The contribution of increased diabetes prevalence and improved myocardial infarction and stroke survival to the increase in treated end-stage renal disease. J Am Soc Nephrol 2003, 14(6):1568-1577.

5. Port FK: The end-stage renal disease program: trends over the past 18 years. Am J Kidney Dis 1992, 20(1 Suppl 1):3-7.

6. Jager KJ, van Dijk PC, Dekker FW, Stengel B, Simpson K, Briggs JD: The epidemic of aging in renal replacement therapy: an update on elderly patients and their outcomes. Clin Nephrol 2003, 60(5):352-360.

7. Lamping DL, Constantinovici N, Roderick P, Normand C, Henderson L, Harris S, Brown E, Gruen R, Victor C: Clinical outcomes, quality of life, and costs in the north thames dialysis study of elderly people on dialysis: a prospective cohort study. Lancet 2000, 356(9241):1543-1550.

8. Brogan D, Kutner NG, Flagg E: Survival differences among older dialysis patients in the southeast. Am J Kidney Dis 1992, 20(4):376-386.

9. Letourneau I, Ouimet D, Dumont M, Pichette V, Leblanc M: Renal replacement in end-stage renal disease patients over 75 years old. Am J Nephrol 2003, 23(2):71-77.
10. Villar E, Remontet L, Labeeuw M, Ecochard R: Effect of age, gender, and diabetes on excess death in end-stage renal failure. J Am Soc Nephrol 2007, 18(7):2125-2134.

11. Foley RN, Parfrey PS, Sarnak MJ: Clinical epidemiology of cardiovascular disease in chronic renal disease. Am J Kidney Dis 1998, 32(5 Suppl 3):S112-S119.

12. Canaud B, Tong L, Tentori F, Akiba T, Karaboyas A, Gillespie B, Akizawa T, Pisoni RL, Bommer J, Port FK: Clinical practices and outcomes in elderly hemodialysis patients: results from the Dialysis Outcomes and Practice Patterns Study (DOPPS). Clin J Am Soc Nephrol 2011, 6(7):1651-1662.

13. Couchoud C, Stengel B, Landais P, Aldigier JC, de Cornelissen F, Dabot C, Maheut $H$, Joyeux V, Kessler M, Labeeuw $M$, et al: The renal epidemiology and information network (REIN): a new registry for end-stage renal disease in France. Nephrol Dial Transplant 2006, 21(2):411-418.

14. Valls J, Cleries R, Galvez J, Moreno V, Gispert R, Borras JM, Ribes J: RiskDiff: a web tool for the analysis of the difference due to risk and demographic factors for incidence or mortality data. BMC Publ Health 2009, 9:473.

15. Bashir S, Esteve J: Analysing the difference due to risk and demographic factors for incidence or mortality. Int J Epidemiol 2000, 29(5):878-884.

16. Munshi SK, Vijayakumar N, Taub NA, Bhullar H, Lo TC, Warwick G: Outcome of renal replacement therapy in the very elderly. Nephrol Dial Transplant 2001, 16(1):128-133.

17. Couchoud C, Moranne O, Frimat L, Labeeuw M, Allot V, Stengel B: Associations between comorbidities, treatment choice and outcome in the elderly with end-stage renal disease. Nephrol Dial Transplant 2007, 22(11):3246-3254.

18. Kurella M, Covinsky KE, Collins AJ, Chertow GM: Octogenarians and nonagenarians starting dialysis in the United States. Ann Intern Med 2007, 146(3):177-183.

19. Hsu CY, Vittinghoff $E$, Lin F, Shlipak MG: The incidence of end-stage renal disease is increasing faster than the prevalence of chronic renal insufficiency. Ann Intern Med 2004, 141(2):95-101.

20. McDonald S, McCredie M, Williams S, Stewart J: Factors influencing reported rates of treated end-stage renal disease. Adv Chronic Kidney Dis 2005, 12(1):32-38.

21. Nesrallah GE, Suri RS, Moist LM, Cuerden M, Groeneweg KE, Hakim R, Ofsthun NJ, McDonald SP, Hawley C, Caskey FJ, et al: International quotidian dialysis registry: annual report 2009. Hemodial Int 2009, 13(3):240-249.

22. Schmieder RE, Mann JF, Schumacher H, Gao P, Mancia G, Weber MA, McQueen M, Koon T, Yusuf S: Changes in albuminuria predict mortality and morbidity in patients with vascular disease. J Am Soc Nephrol 2011, 22(7):1353-1364.

23. Zhang Y, Thamer M, Kaufman JS, Cotter DJ, Hernan MA: High doses of epoetin do not lower mortality and cardiovascular risk among elderly hemodialysis patients with diabetes. Kidney Int 2011, 80(6):663-669.

24. Pfeffer MA, Burdmann EA, Chen CY, Cooper ME, de Zeeuw D, Eckardt KU, Feyzi JM, Ivanovich P, Kewalramani R, Levey AS, et al: A trial of darbepoetin alfa in type 2 diabetes and chronic kidney disease. N Engl J Med 2009, 361(21):2019-2032.

25. Abbott KC, Glanton CW, Trespalacios FC, Oliver DK, Ortiz MI, Agodoa LY, Cruess DF, Kimmel PL: Body mass index, dialysis modality, and survival: analysis of the united states renal data system dialysis morbidity and mortality wave II study. Kidney Int 2004, 65(2):597-605.

26. Winkelmayer WC, Glynn RJ, Mittleman MA, Levin R, Pliskin JS, Avorn J: Comparing mortality of elderly patients on hemodialysis versus peritoneal dialysis: a propensity score approach. J Am Soc Nephrol 2002, 13(9):2353-2362.

27. Couchoud C, Labeeuw M, Moranne O, Allot V, Esnault V, Frimat L, Stengel B: A clinical score to predict 6-month prognosis in elderly patients starting dialysis for end-stage renal disease. Nephrol Dial Transplant 2009, 24(5):1553-1561.

28. Rockwood K, Stadnyk K, MacKnight C, McDowell I, Hebert R, Hogan DB: A brief clinical instrument to classify frailty in elderly people. Lancet 1999, 353(9148):205-206.

29. Sens F, Schott-Pethelaz AM, Labeeuw M, Colin C, Villar E: Survival advantage of hemodialysis relative to peritoneal dialysis in patients with end-stage renal disease and congestive heart failure. Kidney Int 2011, 80(9):970-977.

30. Quinn RR, Hux JE, Oliver MJ, Austin PC, Tonelli M, Laupacis A: Selection bias explains apparent differential mortality between dialysis modalities. J Am Soc Nephrol 2011, 22(8):1534-1542. 
31. Fang W, Yang X, Kothari J, Khandelwal M, Naimark D, Jassal SV, Bargman J, Oreopoulos DG: Patient and technique survival of diabetics on peritoneal dialysis: one-center's experience and review of the literature. Clin Nephrol 2008, 69(3):193-200

32. Lim WH, Dogra GK, McDonald SP, Brown FG, Johnson DW: Compared with younger peritoneal dialysis patients, elderly patients have similar peritonitis-free survival and lower risk of technique failure, but higher risk of peritonitis-related mortality. Perit Dial Int 2011, 31(6):663-671.

33. Sotirakopoulos NG, Kalogiannidou IM, Tersi ME, Mavromatidis KS: Peritoneal dialysis for patients suffering from severe heart failure. Clin Nephrol 2011, 76(2):124-129

34. Loos C, Briancon S, Frimat L, Hanesse B, Kessler M: Effect of end-stage renal disease on the quality of life of older patients. J Am Geriatr Soc 2003, 51(2):229-233.

doi:10.1186/1471-2369-14-131

Cite this article as: Glaudet et al:: The clinical status and survival in elderly dialysis: example of the oldest region of France. BMC Nephrology 2013 14:131.

\section{Submit your next manuscript to BioMed Central and take full advantage of:}

- Convenient online submission

- Thorough peer review

- No space constraints or color figure charges

- Immediate publication on acceptance

- Inclusion in PubMed, CAS, Scopus and Google Scholar

- Research which is freely available for redistribution 